\title{
BEHAVIOUR AND FEMALE REPRODUCTIVE CYCLES OF RHESUS MACAQUES
}

\author{
T. E. ROWELL* \\ Sub-Department of Animal Behaviour, Madingley, Cambridge
}

(Received 21 st January 1963)

\begin{abstract}
Summary. Some of the behaviour of rhesus monkeys, including mating, associating with males, and fighting, is related to seasonal variation, long-term reproductive cycles, and to the menstrual cycle of the females. There was a recognizable breeding season in the colony studied. No behavioural modifications were associated with ovulation, and maximum mating frequency occurred at an infertile stage of the cycle. There were striking behavioural changes associated with menstruation. It is suggested that the term oestrus is not very useful when applied to this species or others with comparable patterns of behaviour.
\end{abstract}

\section{INTRODUCTION}

Rhesus monkeys, like other monkeys and apes, have a menstrual cycle. In this paper changes in behaviour associated with this cycle are investigated. In particular it seemed necessary to reconsider the use of the term oestrus in relation to this species. Oestrus means a period of behavioural sexual receptivity, and an oestrous cycle is one in which periods of receptiveness alternate with periods of unwillingness to mate. The term should describe behaviour, not physiology. Because it has been used chiefly in connexion with domestic animals and laboratory rodents, however, the term has come to have physiological implications, at least for the non-physiologist. Oestrus is assumed to mean a relatively short period at the time of ovulation, marked by striking changes in behaviour, and during which conception can occur. In primate work this use probably stems from Zuckerman (1932) and is implicit in the work of Carpenter (1942) and other primate behaviourists since then. Bingham (1929) put forward the theory that one of the trends in primate evolution is the lengthening of the time in which the female is willing to mate, allowing social units to be built up on continuous sexual bonds. This idea is weakened by the fact that two of the most highly evolved Old World primates, the baboons and the chimpanzee, have developed a cyclical swelling which reaches maximum size about the time of ovulation, and there is evidence that mating is practically confined to the time of maximum swelling in the baboons (Kummer, 1957; Washburn \& DeVore, 1961) and greatly increased during that time in the chimpanzee (Yerkes, 1943). These animals can be said to have an oestrous period, in both the correct and the popular sense. It is perhaps unfortunate that the social

* Present address: Department of Zoology, Makerere University College, Kampala, Uganda. 
behaviour of these species should be the most thoroughly studied among nonhuman primates, because striking external signs of ovulation are not typical of the Order. It is of practical as well as theoretical importance to know whether monkeys without external signs of ovulation also show behavioural changes at this time, because we must know if this is to be taken into account when making long-term behaviour studies. Cyclical changes in the external appearance of rhesus monkeys have been described (Zuckerman, van Wagenen \& Gardner, 1938) and they are discussed later, but with the exception of bleeding from the vulva at the end of the luteal phase of the cycle they are much too variable to be useful indications of physiological state.

Under natural conditions the healthy adult female undergoes relatively few menstrual cycles, and her long-term reproductive cycles consist mainly of pregnancy and lactation. Repeated menstrual cycles are typical of sub-adult females, or of captivity. Behaviour of females undergoing menstrual cycles has been compared with that of other females, so that behaviour in this relatively unusual state can be seen in better perspective.

\section{MATERIAL AND METHODS}

Fifteen female rhesus monkeys were kept in a colony near Cambridge, England, and their behaviour was observed daily for a period of 18 months. The records made were primarily used in colony management; the following points were recorded: (1) Blood or semen on vulva. (2) Colour of rump, nipples, and face, and whether the colour of the rump extended forward along the belly; colour intensity was rated on a six point scale, by eye. (3) Swelling of sex skin. (4) Which other monkeys she groomed, was groomed by, or just sat with. (5) Copulations. All mountings by adult males were included, with no discrimination according to whether or not ejaculation took place, for example. (6) Aggression towards others. (7) Bite wounds. (8) The order in which they came for vitamin pills, which gives a rough guide to rank, and shows rank changes.

All the behavioural points (except taking vitamins) were recorded whenever they were noticed during the day: usually 3 or $4 \mathrm{hr}$ were spent with the colony each day.

The animals lived in groups of three or four females with one male in fairly large outdoor runs (Hinde \& Rowell, 1962). They were not handled at all as long as they were healthy, so that behaviour was not often disturbed; on the other hand, this also meant that the data were no better than could be obtained from field observation. The monkeys had mostly been in the colony about 6 months before these observations were started.

The period under discussion included all or part of eleven pregnancies, seven of which resulted in live births and were followed by lactation, during the early part of which menstrual cycles did not occur. Two of the animals showed no observable cycles because of pregnancies and lactations. Two abortions and one stillbirth were also followed by 1 or 2 acyclic months. One female showed very slight menstrual bleeding, so that only six of her cycles could be followed during the whole 18 months. Two young females began to menstruate during the first 2 or 3 months of observation, and one female was added half 
way through. This left a total of 144 cycles. During some holiday periods, and on Sundays, detailed records were not made. Table 1 shows the number of days in each calendar month on which complete records were kept.

TABLE 1

NUMBER OF DAYS ON WHICH FULL RECORDS WERE MADE IN EACH CALENDAR MONTH OF THE OBSERVATION PERIOD

\begin{tabular}{l|c|c|c|c|c|c|c|c|c|c|c|c}
\hline & fan. & Feb. & Mar. & Apr. & May & fune & July & Aug. & Sept. & Oct. & Nov. & Dec. \\
\hline 1961 & & & 15 & 23 & 22 & 20 & 15 & 23 & 9 & 24 & 24 & 16 \\
1962 & 20 & 24 & 22 & 24 & 21 & 19 & 14 & 23 & 15 & & & \\
\hline Total & 20 & 24 & 37 & 47 & 43 & 39 & 29 & 46 & 24 & 24 & 24 & 16 \\
\hline
\end{tabular}

\section{RESULTS}

EFFECTS OF SEASONS ON REPRODUCTIVE AND SOCIAL BEHAVIOUR

Cambridge is at latitude $53^{\circ} 13^{\prime} \mathrm{N}$, and there are marked seasonal differences in daylength and temperature. It was therefore not surprising to find that acclimatized monkeys that lived mainly outdoors showed seasonal differences in behaviour. Between May and September all the monkeys moulted, though the time that individuals took to replace their coats varied a great deal. Only one animal, in one summer, showed a prolonged amenorrhoea as reported in some colonies, but, as Text-fig. 1 shows, there was a seasonal variation in cycle

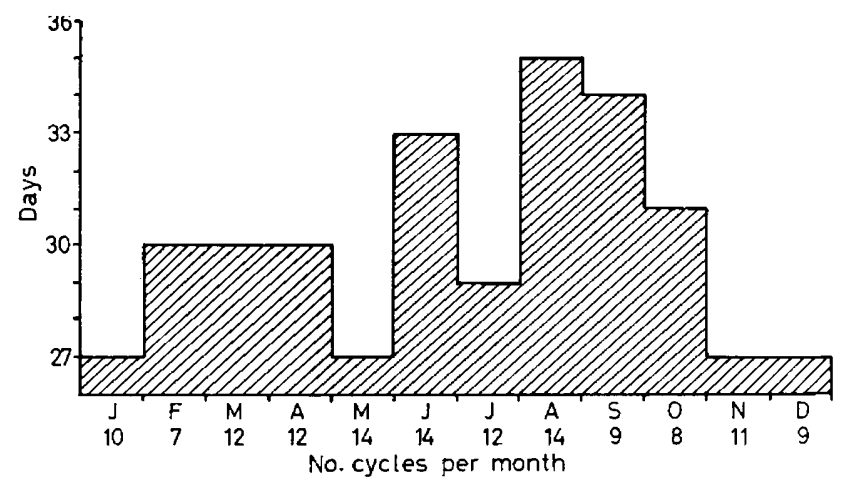

TeXT-FIG. 1. The median length of cycles starting in each calendar month.

length, with shorter cycles in winter than summer. (Median, rather than mean cycle length has been used in Text-fig. 1 to avoid giving undue weight to three cycles of 47, 49 and 53 days, which could indicate something approaching a brief summer amenorrhoea for these animals.)

The shorter cycles were associated with increased fertility, as is seen in Text-fig. 2, so that for this colony it is reasonable to talk of a breeding season.

These seasonal differences were associated with behavioural changes. Text-fig. 3(a) shows the frequency of copulation in each of the four quarters of 
the year. (This includes copulation with pregnant and lactating females.) A female could only score once in a day even if she was mounted repeatedly on that day. There was a big drop in copulation rate in the summer months, and an increase in the last quarter of the year. This relative inactivity in the summer

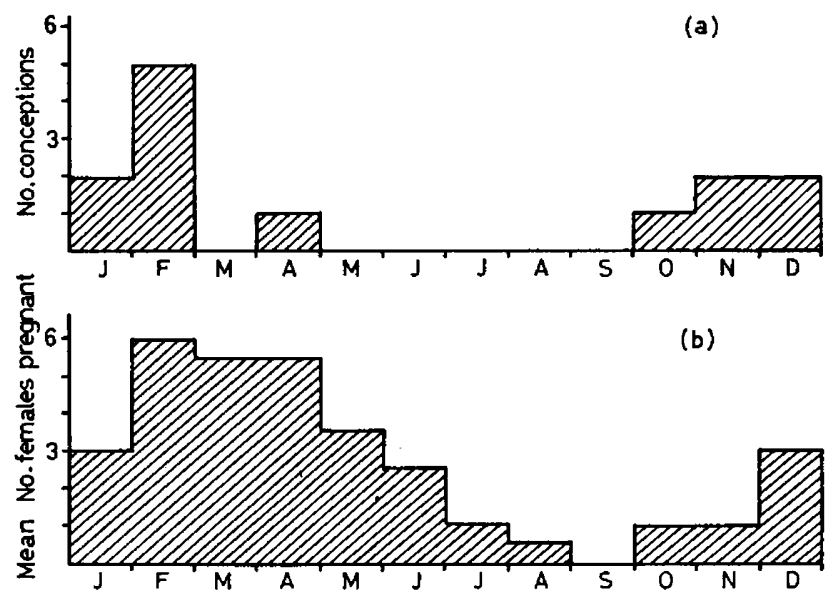

Text-Fig. 2. Annual distribution of breeding in the Madingley colony. (a) Number of conceptions occurring in each calendar month (including four which occurred outside the period of observation). (b) Mean number of females pregnant in each calendar month during the period of observation.

months occurred at the height of the moult, and seemed to affect both sexes. The difference in behaviour was more striking than Text-fig. 3 would indicate,
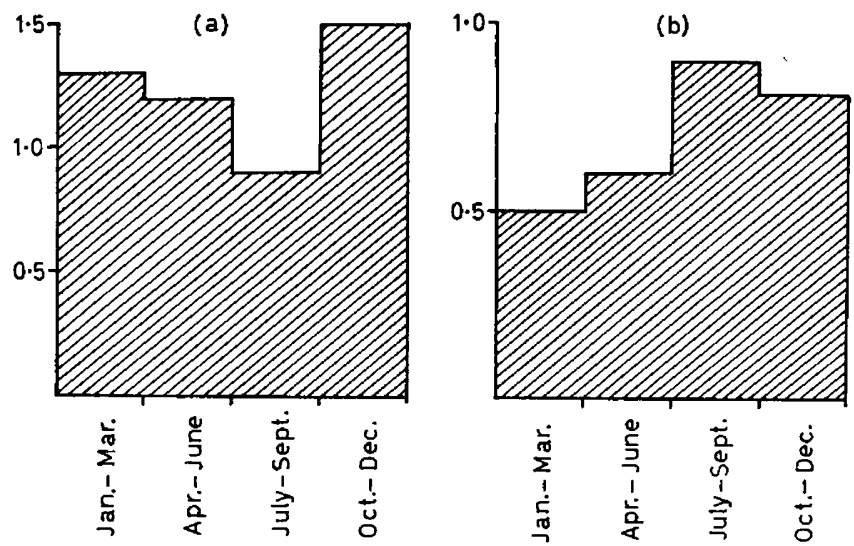

TEXT-FIG. 3. Seasonal variation in behaviour. (a) Mean number of females seen mating per day in the four seasons of the year. (b) Mean number of fights seen each day in the four seasons.

because a higher proportion of mountings at that time were brief and incomplete. The males masturbated frequently, but showed little interest in the females and often sat alone, whereas during the rest of the year they were usually in the company of their favourite female. 
The number of fights per day was high both in the third quarter when copulation rate was low, and in the fourth, when it was at its height [Textfig. 3 (b)]. This was unexpected, because general observation suggested a high correlation between fighting and copulation. The lower level of fighting in the first half of the year might have been related to the increased proportion of pregnant and early lactating females since, as will be seen later, fighting is linked with cyclical changes.

INTRA-CYCLIG DIFFERENCES IN BEHAVIOUR

The difficulty here is in comparing cycles of slightly different lengths. Text-fig. 4 shows the distribution of cycle lengths. Nearly all fall between 24 and 36 days, the median is 30 days, and the figure could reasonably be interpreted as coming

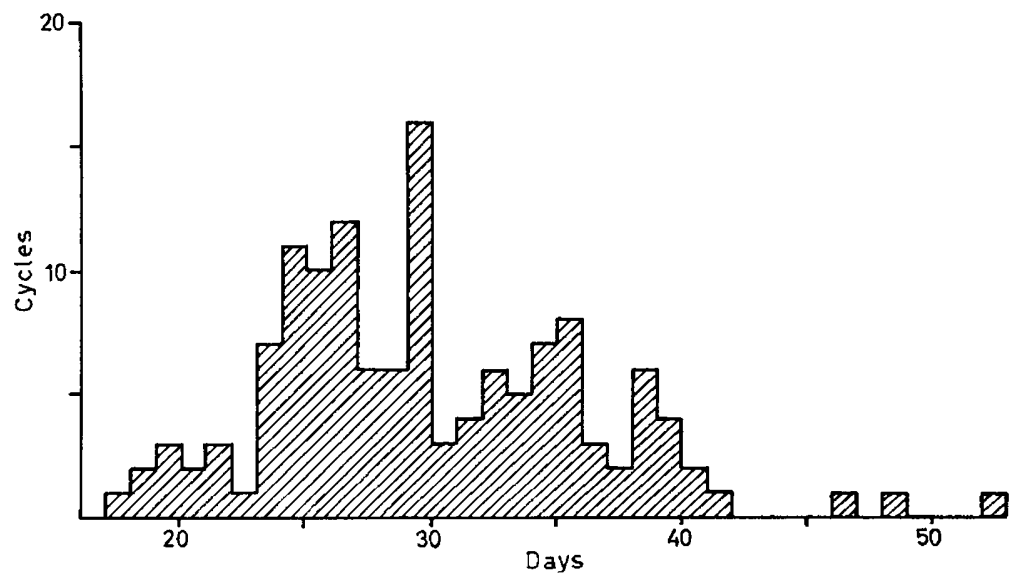

TExT-FIG. 4. Distribution of lengths of menstrual cycles.

from a population with a normal distribution about 30 days. The slight skew towards shorter cycles is probably a collecting bias--more shorter cycles can occur in a given time. Onset of menstruation has been taken as the fixed point marking the beginning of the cycle. Cycles can be compared by counting the days before menstruation or after menstruation. In either case, because of the variation in length, the further away from the fixed point of menstruation the less meaningful the graph becomes, and when counting in either direction the number of cycles diminishes rapidly after 26 days.

It is assumed that menstruation follows ovulation by a fairly rigid interval, which means that the most satisfactory way to count is 'days before menstruation', the variable part of the cycle being the follicular rather than the luteal phase. However, in practice, when trying to make controlled mating for example, one must count forward from menstruation, and this is also the only way to get a clear picture of immediately post-menstrual changes. Thus for most figures both methods of counting are shown, using the same data for both sides of menstruation. In reading the histograms, it should be remembered that the first 26 days are fairly accurate on either side, and the tail of each conveys little information. The histograms are all smoothed by using 2-day means to 
eliminate some of the variation due to small numbers. Ovulation is assumed to occur between Days -16 and -19 , or +11 and +14 , following von Wagenen (1945). (In this colony three of four females controlled mated on Days +9 to +14 conceived first time.)

\section{Copulation}

Text-fig. 5(a) shows the number of copulations per day of the cycle. There was no suggestion of a peak about the time of ovulation, in fact over 3 weeks in mid-cycle there was very little change in rate, though there were suggestions of
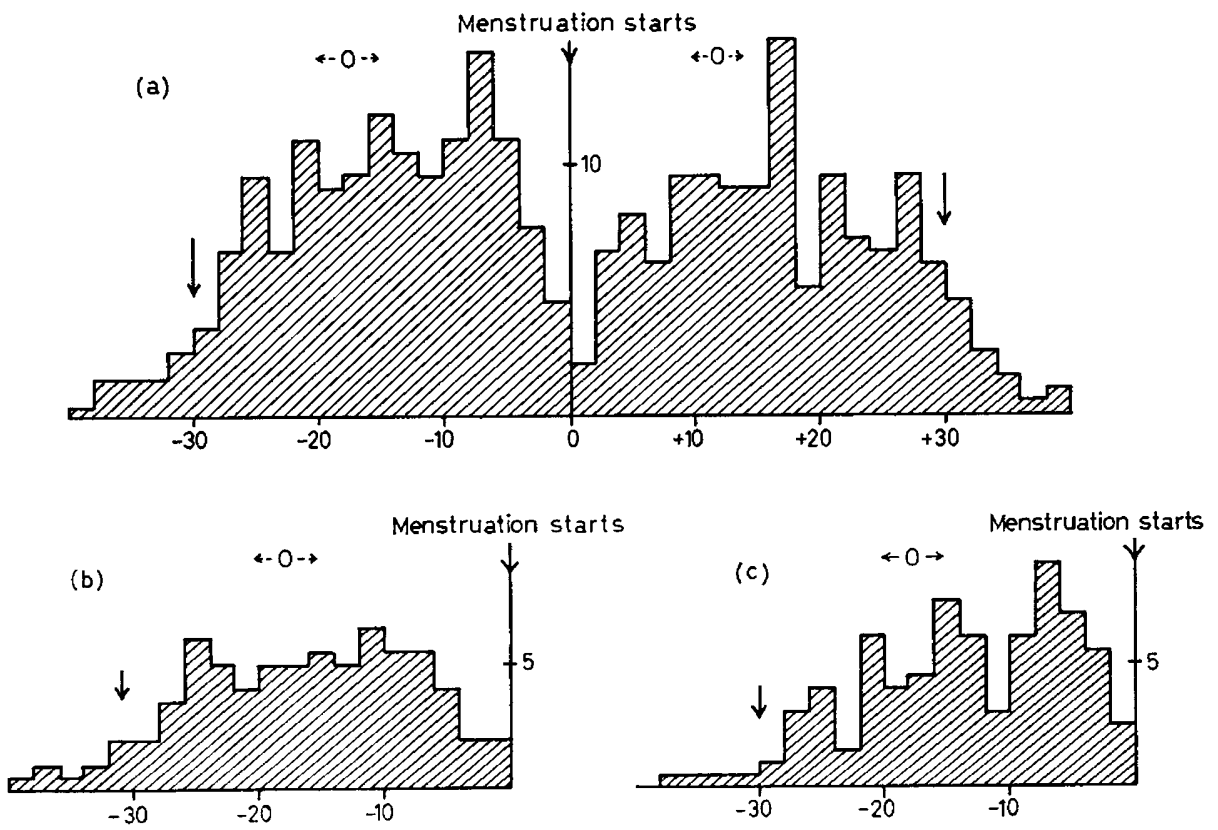

TEXT-FIG. 5. Copulations. (a) Number of copulations on each day of the cycle. Arrows mark median cycle length. Period during which ovulations probably occurred is indicated (O). Each column is the mean of 2 days. (b) Copulations by two favourites. (c) Copulations by eleven other females.

peaks occurring at about 8 days before menstruation, or 17 days after it. There was, however, a sharp decrease in copulation in the 4 to 6 days before menstruation, and a rapid increase in the first 4 days of the cycle.

There were big differences in the amount of copulation by different females. During the period of observation two of the males had 'favourite wives', with whom they ordinarily sat and groomed, and whom they defended if necessary from other females. These two females retained their position as favourites almost continuously regardless of cycle state. This status was not related to rank. One favourite was the lowest ranking female, the other began as lowest ranking and became dominant as she became older and healthier. These two females accounted for half the copulation recorded. Copulations with nonfavourites were either occasional isolated matings, or occurred when a female which usually ignored the male 'took him over' for a few days, continuously 
mating, grooming, soliciting, etc. This was the nearest we saw to the classic description of rhesus sexual behaviour by Carpenter (1942), but it only happened three or four times and was always accompanied by an unusual amount of fighting and disturbance. Text-figs. 5(b) and (c) show the distribution (in days before menstruation only) of copulations for the two favourites compared with the other eleven cycling females. Allowing for the variation produced by smaller numbers, the two groups do not differ much. Perhaps the peak towards the
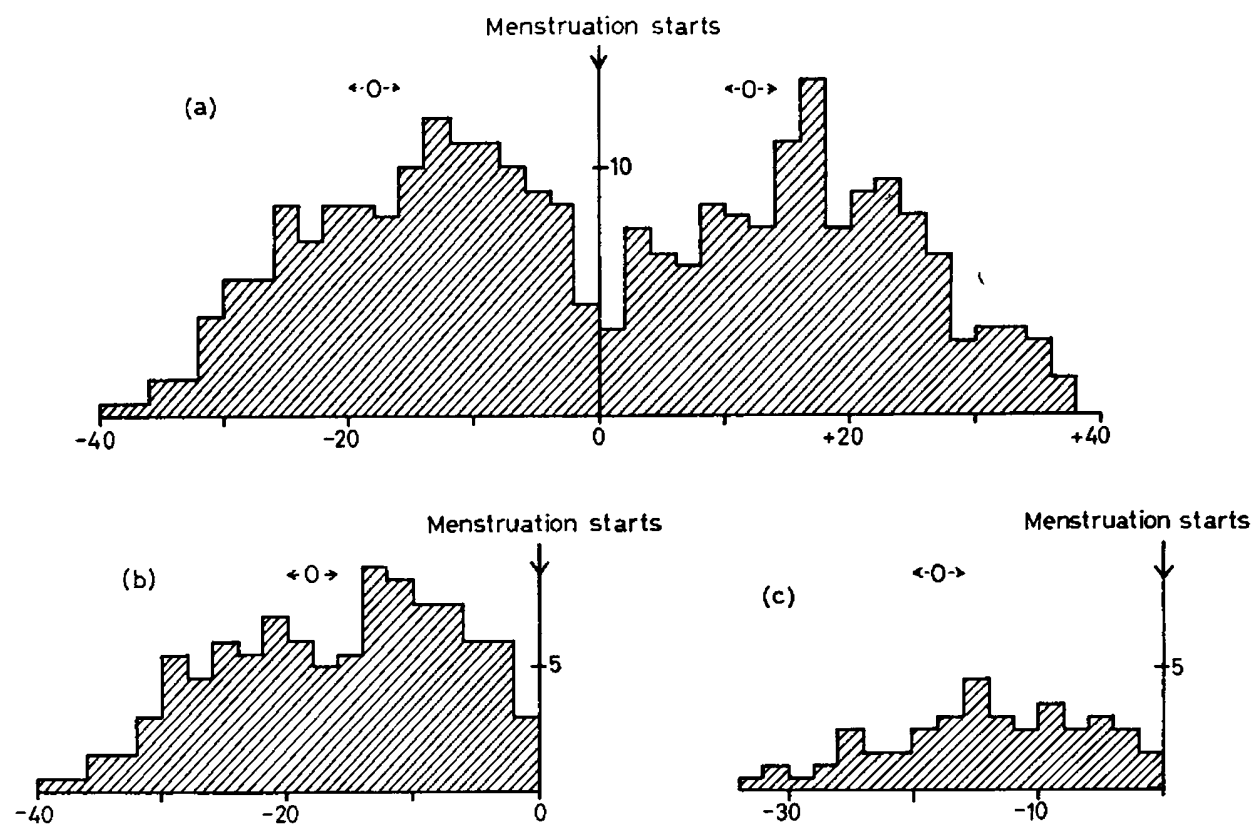

Text-FIG. 6. Sitting with male. (a) Number of records of sitting with male on each day of the cycle. Period during which ovulations probably occurred is indicated (O). Each column is the mean of 2 days. (b) Two favourite females sitting with males. (c) Eleven other females sitting with males.

end of the cycle is more exaggerated in non-favourite females. This supports a subjective impression that some non-favourites seem to take so long in each cycle to pluck up courage to present to the male that they had passed the fertile period before they copulated.

Sitting with males

Only a small proportion of copulations could be seen in the 3 or $4 \mathrm{hr}$ available, but the male usually copulates with the female sitting near him, so that it is highly probable that a female seen sitting huddled to the male, grooming or being groomed by him, will mate during the day. Text-fig. 6(a) shows the days of the cycle on which this behaviour occurred. The distribution is very similar to that of copulations, perhaps there are more pronounced peaks about Day -13 or +17 , a more gradual rise and fall, and therefore less of a mid-cycle plateau. Text-figs. 6(b) and (c) show the same behaviour, with the two favourites separated from the eleven other females. As can be seen, nearly all sitting 
with males was done by the favourites. None of the non-favourites sat with a male on the day before menstruation, and during the rest of their cycles the records are too few to show any inequalities of distribution.

Fighting and rank changes

Fighting, and establishment of rank by threats and postures, is extremely complex in a monkey group: for example, fights are rarely confined to the two

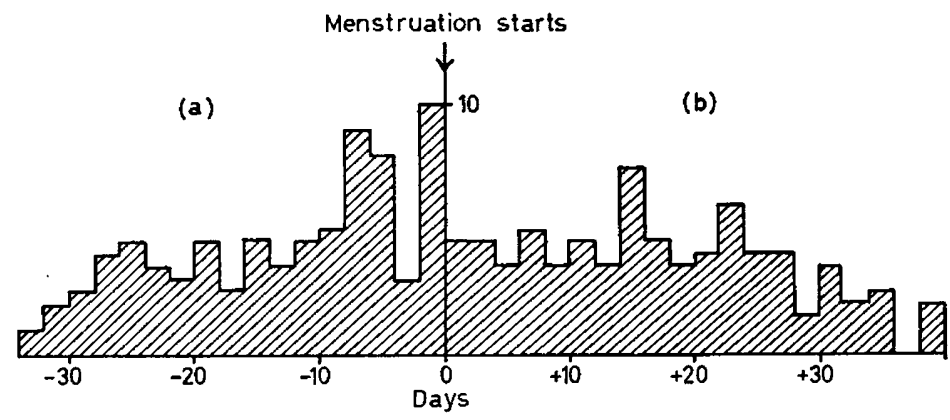

TeXT-FIG. 7. Females attacked or bitten on each day of the cycle. Each column is the mean of 2 days. Section (a) shows an increase just before menstruation which is lost in the tail of Section (b).

animals originally involved in a situation, and friendship and kinship'links help to determine the outcome, so that to relate these activities to reproductive cycles adequately will need more information than has so far been collected. Text-figs. 7 and 8 show the time in their cycles when females were attacked, and when they

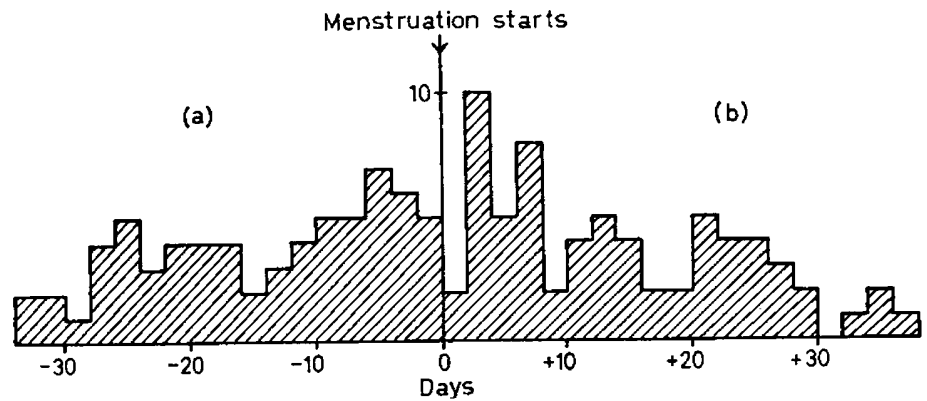

Text-Fig. 8. Aggression by females on each day of the cycle. Each column is the mean of 2 days. Section (b) shows an increase just after menstruation which is lost in the tail of Section (a).

were the aggressors. Text-fig. 7(a) shows an increase in being attacked during the last week of the cycle; Text-fig. 8(b) shows an increase in aggression in the first week of the cycle. Aggression was especially frequent on Day +3 , that is, just as menstrual bleeding ended. (Text-figs. $7(\mathrm{~b})$ and $8(\mathrm{a})$ do not show these trends because the changes are abrupt, and are lost because of different cycle lengths in the tails of these histograms.) 
Taking vitamin pills also fitted into this picture. Monkeys came in turn to take pills offered by the observer, roughly in order of rank, dominant male first. It required a considerable degree of confidence, both to approach the observer and to turn their backs on potential aggressors. There was a tendency for females to come later, or refuse to come at all, during and just preceding menstruation. The same tendency was seen in females with new babies, and it was also one of the first signs of illness.

\section{Changes in colour}

Monkeys differ a great deal in the intensity and type of colour of the hairless parts of their bodies. In some the basic colour is purplish-pink, in others an orange-scarlet. The amount these colours change also varies-some individuals

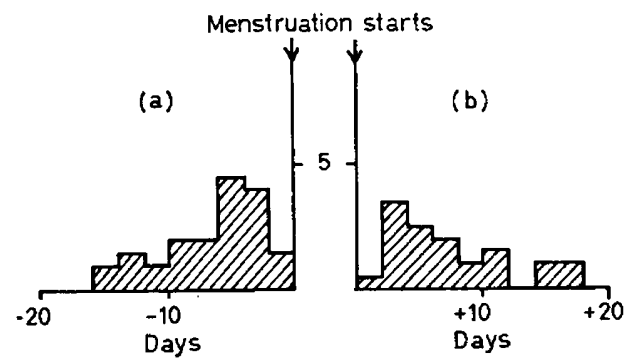

TeXT-FIG. 9. Cyclical colour changes. (a) Days of cycle on which colour began to decrease in intensity. (b) Days of cycle on which colour began to increase in intensity.

never show colour changes on the face, for example, while in others face colour fluctuates strikingly, and the same variations are seen for nipple, belly, and rump colours. Colour intensity in these areas increases rapidly if there is a fight or other excitement, and usually drops if an animal is put in a small cage alone. Putting a male with an isolated female can raise her colour intensity within a few hours. The impression gained was that behaviour, such as copulation, influenced colour intensity, rather than vice versa. Colour intensity also changes under the influence of hormones, as is well known. In particular, females become very bright in late pregnancy, then become pale after parturition and remain pale during lactation. Colour changes also occur during menstrual cycles, and an increase in intensity at mid-cycle has been associated with high oestrogen levels. These changes are not so marked that an observer unfamiliar with a particular individual could recognize at what stage in her cycle she was. Of 144 menstrual cycles, thirty-seven (about one-quarter) were associated with obvious cyclical colour changes. Text-fig. 9 shows the time relations of these colour cycles: typically the colour began to increase in intensity about 4 to 6 days after menstruation, and decreased 3 to 7 days before the next menstruation; half the cases fall into this range. Other females also showed colour changes, but fluctuated too rapidly and erratically to be called cyclical. Young females also became swollen on the rump, the root of the tail, and the back of the hind legs. This swelling occurred in the second half of the menstrual cycle, once the cycle was established, but again there were large day-to-day variations. 
No changes in behaviour by or towards the animal concerned could be related directly to these changes in appearance.

\section{Effect of other reproductive activities}

During the period of observation there were, in addition to the 144 menstrual cycles, 1937 days of pregnancy and 529 days between births and cycles restarting, the period referred to as lactation, though in fact the mothers continued to nurse long after menstruation was resumed. Rates of occurrence of some of the activities discussed are shown in Table 2. Copulation was half as frequent

TABLE 2

FREQUENCY OF SOME ACTIVITIES IN FEMALES IN THREE DIFFERENT REPRODUCTIVE STATES GIVEN AS NUMBER OF OBSERVATIONS PER FEMALE-DAY

\begin{tabular}{|c|c|c|c|c|c|}
\hline & Copulation & $\begin{array}{l}\text { Sitting } \\
\text { with male }\end{array}$ & Aggression & $\begin{array}{l}\text { Being } \\
\text { bitten }\end{array}$ & $\begin{array}{l}\text { Total No. } \\
\text { female-days }\end{array}$ \\
\hline $\begin{array}{l}\text { In menstrual cycle } \\
\text { Favourites } \\
\text { Non-favourites } \\
\text { Pregnant } \\
\text { Lactating }\end{array}$ & $\begin{array}{l}\left.\begin{array}{l}0.21 \\
0.039 \\
0.033 \\
0.019\end{array}\right\} 0.066 \\
0.04\end{array}$ & $\begin{array}{l}\left.\begin{array}{l}0.23 \\
0.02 \\
0.036 \\
0.015\end{array}\right\} 0.063 \\
0\end{array}$ & $\begin{array}{l}0.015 \\
0.021 \\
0.01\end{array}$ & $\begin{array}{l}0.022 \\
0.016 \\
0.025\end{array}$ & $\left.\begin{array}{l}690\} \\
3630 \\
1659 \\
529\end{array}\right\} 4320$ \\
\hline
\end{tabular}

in pregnant animals as in those undergoing menstrual cycles, taken together. When favourite and non-favourite cycling females were separated, the rate of copulation in the latter was found to be roughly the same as that for pregnant animals - roughly one-fifth of the rate for favourites. Lactating females copulated far less often than others. Sitting with male followed the same pattern as copulation, as before. Favourites and non-favourites are even more different in this respect, and pregnant females sat with males more often than non-favourite cycling animals. This is probably because one of the favourites had two abortive pregnancies, which underlines the importance of individual differences in small samples. Pregnant females were on the whole more aggressive, and were bitten less often, than cycling females; lactating females were slightly less aggressive than cycling females, and were perhaps bitten very slightly more.

\section{GONCLUSION}

The general picture that emerges of the behaviour of the female rhesus monkey through the menstrual cycle is as follows: immediately after menstruation she becomes aggressive to other females, begins to approach the male, and sometimes copulates. Her confidence reaches a fairly high level in a few days and the time she spends with the male, and the frequency with which she mates, continues to increase slowly until a few days before the next menstruation. Then quite suddenly she begins to get attacked and bitten frequently, becomes timid, leaves the male, and reaches her lowest status the day before the next menstruation.

This picture calls into question the usefulness of the term 'oestrus' as it is often applied to rhesus monkeys. It would be correct to regard a period between 
about the 4 th and the 26 th day of the 30 -day cycle as an oestrous period. In the group of females studied, there was no special behaviour associated with ovulation, and mating was, in fact, most frequent at an infertile part of the cycle. On the other hand, there were striking behavioural changes in the 5 or 6 days around the onset of menstruation. To think of the mid-cycle behaviour as being usual, and interrupted by short periods of 'menstrual behaviour', would therefore seem more useful than to think of the cycle punctuated chiefly by 'oestrus'. This distinction is more than a play on words, it requires a change of approach which could be important. It suggests that primates (including women) which do not show obvious external signs of ovulation, and may have no clearly defined oestrus, might build societies on a rather different basis from those of the baboons and the chimpanzee; at least care must be taken in extrapolating from one to the other.

The slight tendency to mate after the fertile part of the cycle may be only an artefact of captivity, but if not it provides a situation on which selection could possibly have acted to produce the sexual swellings of baboons, chimpanzees and some macaques, which seem at first sight to be an extremely unadaptive modification. Here, however, is a possible reason for better synchronization between behaviour and physiology being able to increase the efficiency of reproduction.

\section{ACKNOWLEDGMENTS}

This work was supported by the Medical Research Council and the Mental Health Research Fund. I am grateful too to Dr R. A. Hinde, who made some of the observations, and Professor A. S. Parkes, C.B.E., F.R.S., who helped with discussion, and by defining menstrual and oestrous cycles.

\section{REFERENCES}

Bingham, H. C. (1929) Sex development in apes. Comp. psy. Monogr. 5, 1.

Garpenter, C. R. (1942) Sexual behaviour of free ranging Rhesus monkeys. 7. comp. Psychol. $33,113$. Hinde, R. A. \& Rowell, T. E. (1962) Communication by postures and facial expressions in the Rhesus monkey. Proc. zool. Soc. Lond. 138, 1.

Kummer, H. (1957) Sociales verhalten einer Mantelpavian Gruppe. Schweiz. Z. Psychol. 33, 1.

Rowell, T. E. \& Hinde, R. A. (1962) Vocal communication by the Rhesus monkey. Proc. zool. Soc. Lond. 38, 279.

Van Wagenen, G. (1945) Optimal mating time for pregnancy in the monkey. Endocrinology, $37,307$.

Washburn, S. \& DeVore, I. (1961) The social life of baboons. Sci. Amer. 204, 62.

Yerkes, R. M. (1943) Chimpanzees: a laboratory colony. Yale University Press.

Zuckerman, S. (1932) The social life of monkeys and apes. Kegan Paul, London.

Zuckerman, S., van Wagenen, G. \& Gardner, R. H. (1938) The sexual skin of the rhesus monkey. Proc. zool. Soc. Lond. 108, 385. 